Issn: 1808 - 799X

ano 14, número $24-2016$

\title{
PROJETOS PROFISSIONAIS DE JOVENS ESTUDANTES NO CONTEXTO DE FLEXIBILIZAÇÃO DO TRABALHO
}

\author{
Camila Felipe Tonn ${ }^{1}$ \\ Luciana Pedrosa Marcassa²
}

\section{Resumo}

Esse texto discute as ideias e valores que compõem os projetos profissionais de jovens estudantes da classe trabalhadora que estão cursando o Ensino Médio em escolas públicas da periferia urbana de Florianópolis - SC. No contexto da reestruturação produtiva e da flexibilização das relações de trabalho, esse jovens fundamentam seus projetos profissionais segundo os padrões de "empregabilidade" então requeridos, submetendo suas capacidades humanas criadoras, não a uma atividade realizadora, mas a uma atividade que reproduz sua condição de classe, enquanto favorece a expansão do capital.

Palavras-chave: trabalho, educação, projetos profissionais

\begin{abstract}
This paper debate ideas and values that compose the professional projects of young students from the working class who are enrolled in secondary education in public schools in the urban outskirts of Florianópolis - SC. In the context of produtive restructuring and the flexibility of labor relations, that young base their professional projects according to the standards of "employability" then required, submitting their human creative powers, not of accomplish activity, but an activity that plays its condition class, while furthering the expansion of capital .
\end{abstract}

Keywords: work; education, professional projects

As constantes transformações no mundo do trabalho estão sempre a exigir novas qualificações e requisitos daqueles que precisam se inserir no mercado.

\footnotetext{
1 Mestranda em Educação pelo PPGE/UFSC, linha trabalho e educação. Pesquisadora do TMT/UFSC. (camila.tonn@gmail.com).

2 Professora do Centro de Ciências da Educação da UFSC e do PPGE - Programa de PósGraduação em Educação da UFSC. Pesquisadora do TMT/UFSC. (luciana.marcassa@ufsc.br)
} 


\section{Trabalhonecessário}

Issn: 1808 - 799X

ano 14, número $24-2016$

Em se tratando de jovens estudantes, a elaboração de seus projetos profissionais se liga às expectativas abertas por sua formação e nível socioeconômico e cultural, mas também à eficácia que determinadas credenciais oferecem como garantia desse acesso. Neste texto ${ }^{3}$, procuramos refletir sobre as ideias e valores que concorrem para a elaboração dos projetos profissionais de jovens estudantes de escolas públicas ${ }^{4}$ da região do maciço central do Morro da Cruz (MMC) em Florianópolis, a fim de descortinar os elementos que são incorporados pelos jovens como passaporte necessário para inserção no mercado de trabalho.

O maciço do Morro da Cruz (MMC) é um vasto território formado por um bloco rochoso alongado que, segundo dados da Prefeitura de Florianópolis (2009), equivale a 2,1 milhões de metros quadrados, com uma população total estimada em 22.708 moradores, distribuídos entre 17 comunidades, isto é, 675 mil metros quadrados são de ocupação humana ${ }^{5}$. Apesar de situar-se na porção central da Ilha de Santa Catarina, é quase invisível à maioria da população, já que não integra o cenário "paradisíaco" da cidade. Ao contrário, a região é considerada periférica e caracterizada pelo aglomerado de habitações precárias, cujos moradores sofreram durante muito anos a completa ausência de serviços e de investimentos públicos e mesmo de reconhecimento de seus direitos como cidadãos.

As escolas próximas ao MMC recebem os jovens desses territórios, pertencentes às frações mais empobrecidas da classe trabalhadora, para a qual

\footnotetext{
${ }^{3}$ Este texto, quem vem sendo desenvolvido como dissertação de Mestrado da primeira autora, faz parte da Pesquisa "Juventude Pobre e Escolarização, relações com a escola, o trabalho e a cultura em territórios de precariedade" coordenada pela Professora Luciana Pedrosa Marcassa e realizada coletivamente pelo Grupo de Estudos e Pesquisas sobre as Transformações no Mundo do Trabalho - TMT/UFSC.

${ }^{4}$ Esta pesquisa se valeu de questionários, grupos focais e entrevistas a estudantes dos anos finais do Ensino Fundamental e, em sua maioria, a estudantes de Ensino Médio, de 10 escolas básicas da Grande Florianópolis, resultando numa amostra de 1180 sujeitos.

${ }^{5}$ Percebe-se que não há consenso em relação ao número de habitantes das comunidades dos morros, muito menos em relação ao número de comunidades existentes, já que algumas ocupações recentes ainda não foram devidamente catalogadas. Para as lideranças comunitárias do maciço do Morro da Cruz, estima-se que existam, praticamente, 30.000 pessoas residindo nos morros, o que equivale a quase $8 \%$ da população absoluta da capital.
} 


\section{Trabalhonecessário}

Issn: 1808 - 799X

ano 14 , número $24-2016$

pouca ou nenhuma outra oportunidade de formação cultural é acessível. Vale dizer que boa parte deles nem conhece as praias mais famosas da Ilha. Isto porque, além da segregação econômica e socioterritorial, segundo dados da nossa pesquisa, $69,5 \%$ desses jovens trabalham ou precisam trabalhar, isto é, os estudantes, seja do diurno ou noturno, trabalham no contra turno ou nos finais de semana, em restaurantes, pizzarias, postos de combustível, redes de fast food, telemarketing, entre outras atividades do tipo "trabalho simples"6. Eis a condição material básica a partir da qual os jovens constroem seus projetos profissionais.

Assim, considerando as condições concretas de vida e de estudo desses jovens, e o mundo do trabalho atual, que ideias e valores são incorporados pelos jovens na elaboração de seus projetos profissionais? Que papel cumpre a escola nesse processo?

\section{A flexibilização das relações de trabalho}

É amplamente difundida a ideia de que, ao construir seus projetos profissionais, os indivíduos devem desenvolver a capacidade de adaptação diante das incertezas e instabilidades, identificando oportunidades, se qualificando, sendo proativos, criativos, resilientes, e o que mais se faça necessário. Isso porque, cada sujeito é visto como o único responsável pela sua própria inserção, permanência e desenvolvimento profissional, autônomo para tomar suas próprias decisões, livre para escolher o que deseja fazer. Esses são os imperativos da vida produtiva contemporânea.

Esses imperativos não são casuais, uma vez que as relações de trabalho têm se tornado cada vez mais flexíveis, pensadas a curto prazo, fazendo-se necessárias apenas enquanto houver uma demanda de produção (Sennet, 2002). Essa realidade corresponde às novas formas de contratação terceirizada, por

\footnotetext{
${ }^{6}$ De acordo com Marx (1996, p. 174), o trabalho simples corresponde àquele "que em média toda pessoa comum, sem desenvolvimento especial, possui em seu organismo físico".
}

TrabalhoNecessário - www.uff.br/trabalhonecessario; Ano 14, №24/2016. 


\section{Trabalhonecessário}

Issn: 1808 - 799X

ano 14 , número $24-2016$

tempo determinado, por hora, por produção, sob forma de prestação de serviços por autônomos ou microempreendedores individuais ${ }^{7}$. Deste modo, diminui-se os custos das empresas com a contratação de força de trabalho, pois ela é utilizada apenas no momento em que se faz necessária, reduzindo os vínculos a longo prazo, com todas as proteções sindicais e direitos previsto em lei.

Essas formas de contratação surgem do rearranjo do modelo produtivo de diversas organizações a partir das décadas de 1970 e 1980, como estratégia para superar a crise de superprodução decorrente do modo fordista de organização do trabalho $^{8}$, marcada pelo excesso de produtos em estoque, intensa competitividade e drástica diminuição das margens de lucro. Para baixar os custos de produção, as organizações entraram num período de reestruturação produtiva e passaram a atuar sob demanda, implementar automação dos processos utilizando insumos tecnológicos, acelerando o tempo de giro da produção (característico do sistema just-in-time ${ }^{9}$ ). Procuraram, também, diversificar as áreas de atuação, investir em terceirização de parcelas do processo produtivo, realizar fusões e incorporações, com o objetivo de aumentar a extensão e permeabilidade dos produtos e serviços em diversas partes do mundo (Harvey, 2002). Esse novo modelo de produção passou a ser conhecido como "modo de produção enxuta", "modo de produção flexível”, "modelo japonês", "modelo Toyota de produção", ou "toyotismo"10.

\footnotetext{
${ }^{7}$ Microempreendedor individual é a pessoa que trabalha por conta própria e que se legaliza como pequeno empresário (Brasil, 2016)

${ }^{8} \mathrm{O}$ fordismo é um padrão de acumulação de capital marcado pela produção em massa, rígida divisão do trabalho, hierarquização da estrutura organizacional e disciplinamento dos trabalhadores, que prosperou num contexto de Estado de bem-estar social, caracterizado pela concessão de benefícios sociais como forma de salários indiretos (Montaño; Duriguetto, 2002)

${ }^{9}$ O sistema just-in-time preconiza que "cada processo deve ser suprido com os itens e quantidades certas, no tempo e lugar certo" (Ghinato, 1995, p. 170), envolve o intenso controle dos processos de trabalho, a fim de garantir zero defeitos e máxima eficiência.

10 Taiichi Ohno, que foi engenheiro-chefe e vice-presidente da Toyota, é um dos criadores e promotores desse modelo que foi desenvolvido na década de 1950 no Japão. Considerando a necessidade de desenvolver a economia japonesa em crise com baixo investimento, utilizou-se da estratégia de diminuir os fatores que representam os maiores custos: a contratação de pessoas e
}

TrabalhoNecessário - www.uff.br/trabalhonecessario; Ano 14, № 24/2016. 


\section{Trabalhonecessário}

Issn: 1808 - 799X

ano 14, número $24-2016$

Apesar da implementação do modelo de produção enxuta ser extensiva, não é unânime em todas as empresas e todas as partes do mundo. Convivendo com empresas altamente tecnológicas, com foco no aumento progressivo da eficiência, atuando sob demanda (como a indústria automobilística), e organizações especializadas na prestação de serviços (como da área de Tecnologia da Informação), estão corporações tradicionais, fundamentadas no trabalho manual, com grandes estruturas hierárquicas (como no segmento frigorífico), a produção agrícola mais elementar (como os agricultores familiares fumicultores), o trabalho no artesanato (como as associações de artesãos), o trabalho ambulante informal (como os camelôs), o trabalho doméstico e o trabalho escravo (como o utilizado em fazendas e na construção civil, sob forma de retenção de salários, aprisionamento e condições degradantes de trabalho).

Sendo assim, o desenvolvimento das forças produtivas configura-se como um desenvolvimento desigual e combinado, processo no qual o "atrasado" ainda está presente e atua na manutenção da expansão do "avançado" (Oliveira, 2003). Por isso, considerando todas as mudanças implementadas a partir da reestruturação produtiva, "o sistema de metabolismo social do capital necessita cada vez menos do trabalho estável e cada vez mais das diversificadas formas de trabalho parcial ou part-time, terceirizado" (Antunes, 2002, p. 175), o que vem promovendo uma transformação na estrutura do mercado de trabalho e pressionando o Estado a rever as legislações de proteção ao trabalhador ${ }^{11}$. Portanto, a flexibilização no contexto da produção determina uma flexibilização nas relações de trabalho, com a alteração nos padrões de contratação, a oferta de postos de trabalho formal e protegido juridicamente diminui progressivamente,

o volume de estoque, para que o processo produtivo fosse flexível e adaptado às variações do mercado (Montaño; Duriguetto, 2002). O modelo ganhou repercussão mundial a partir da crise do petróleo de 1973, momento de estagnação da produção e inflação dos preços (Harvey, 2002).

${ }^{11}$ Exemplos do caso brasileiro são propostas de lei que visam a revisão da Consolidação das Leis de Trabalho de forma a dar mais autonomia na "negociação" entre empregador e empregado como PL 4193/2012; PL 427/2015; PL 1875/2015; PL 7341/2014; PL 8294/2014; PL 3785/2012; PL 5019/2009; PL 2820/2015, entre outros. 


\section{Trabalhonecessário}

Issn: 1808 - 799X

ano 14, número $24-2016$

aumentando a taxa de desemprego em todo mundo, chegando a altos níveis, mesmo em países considerados desenvolvidos como Grécia $(24,4 \%)$, Espanha $(20,9 \%)$, Portugal (12,2\%), Itália (11,7\%), França (10,3\%) e Finlândia $(9,4 \%) .{ }^{12}$

Destarte, o desemprego caracteriza-se como estrutural, impactando todos os segmentos da economia e atingindo desde os trabalhadores não qualificados até os que possuem altos graus de qualificação (Meszáros, 2007). Ao analisar a configuração do mercado de trabalho no contexto da "flexibilidade", Harvey (2002) explicita que há um grupo seleto (que diminui cada vez mais) de postos de trabalho que conferem maior segurança no emprego, perspectivas de promoção e que demandam maior qualificação geral; e na periferia, existem as ofertas de trabalho em tempo integral que exigem habilidades facilmente encontradas no mercado, ligadas à tarefas rotineiras e pouco especializadas e em tempo parcial, contratos por tempo determinado, temporário, subcontrato, terceirizado, sem segurança alguma e requerendo baixíssima qualificação. Nesse contexto, percebe-se um processo de precarização das condições de trabalho, que diminui a proteção ao trabalhador e desonera as organizações contratantes.

Essas mudanças atingem um número cada vez maior de pessoas no mundo, a partir do processo chamado de "globalização" termo que descreve "de maneira supostamente neutra a crescente mobilidade e fluidez de capitais" (Fontes, 2010, p.154). Por considerar que o termo obscurece a realidade, considera-se mais adequado utilizar o conceito de "capital-imperialismo" que descreve a "forma da expansão do capitalismo na segunda metade do século $X X$, e se espraiou nas sociedades secundárias, nas quais se implantou a partir de condições de forte dependência, embora de maneira desigual segundo os países" (Fontes, 2010, p.216). A expansão capital-imperialista ocorre por meio de empresas organizadas como sociedades anônimas e multinacionais, que se deslocam buscando menores custos de produção e força de trabalho, produzindo

\footnotetext{
${ }^{12}$ Dados relativos aos meses de dezembro de 2015 e fevereiro de 2016, de acordo com Trading (2016).
}

TrabalhoNecessário - www.uff.br/trabalhonecessario; Ano 14, № 24/2016. 


\section{Trabalhonecessário}

Issn: 1808 - 799X

ano 14, número $24-2016$

assim maiores margens de lucro, de forma cada vez mais difusa e abstrata (Fontes, 2010). Essa é uma situação que cria uma fluidez ainda maior nas relações de trabalho, pois condiciona a formação padronizada e circulação de trabalhadores pelo mundo. Meszáros (2007, p. 149) indica que os trabalhadores "podem culpar a si mesmos por seu desemprego, porque se recusam a 'circular', em virtude do 'instinto caseiro' que os prende ao lugar onde nasceram e cresceram". Então, percebe-se que a responsabilidade individual aparece como causa das situações de desemprego ou subemprego. Mas, na verdade, o que essa ideia elide, é a exigência capital-imperialista de profissionais multifuncionais, disciplinados, estandardizados e facilmente recicláveis e substituíveis, disponíveis para serem utilizados de forma fluida, conforme a demanda variável de tempo e lugar dos empregadores (Castro, 2004).

\section{Tornar-se empregável: um discurso que oculta a expropriação}

É nessa conjuntura "flexível" que os jovens constroem seus projetos profissionais. Considerando que o desenvolvimento desigual e combinado mantém e cria diversas possibilidades de inserção no mercado de trabalho, que vão desde os poucos postos de trabalho estáveis, até ofertas laborais vulneráveis e precarizadas, percebe-se um aumento progressivo da competição entre os jovens que pretendem se inserir no mercado e entre os próprios trabalhadores que buscam melhores condições de integração ao contexto laboral. Ligado a isso, difundiu-se a ideia da "empregabilidade", ou seja, de que o trabalhador deve ser competitivo, deve desenvolver e apresentar competências (técnicas, comportamentais, intelectuais) que agreguem valor às empresas ${ }^{13}$. Para ser "empregável", os indivíduos necessitam de um quantum de estudo, que permita

${ }^{13}$ Ideia de "agregar valor", na visão empresarial-concorrencial, relaciona-se à capacidade do trabalhador de diferenciar-se daquilo que outros trabalhadores já oferecem ao mercado enquanto força de trabalho, transformada em mercadoria.

TrabalhoNecessário - www.uff.br/trabalhonecessario; Ano 14, № 24/2016. 


\section{Trabalhonecessário}

Issn: 1808 - 799X

ano 14, número $24-2016$

apresentar certas credenciais, as quais devem ser atualizadas constantemente, para que, finalmente, possam se adequar ao perfil preconizado pelo mercado. Essa é uma das ideias que permeiam os projetos profissionais de jovens trabalhadores, ainda que seus percursos escolares sejam, com frequência, interrompidos, em virtude de sucessivas reprovações, da necessidade de trabalhar, das migrações em busca de melhores condições de vida, ou mesmo da desmotivação ou desinteresse dos jovens pela escola ${ }^{14}$.

Os jovens da pesquisa têm clareza de que, entre as credenciais para que se "tornem empregáveis", a escolarização, a formação permanente, o prolongamento dos estudos, a apropriação de conhecimentos gerais e específicos e, ainda, a especialização e administração de uma carreira profissional são habilitações importantes para o alcance desse objetivo, mesmo que implique só a realização de uma promessa, a promessa da empregabilidade (Gentili, 2002).

A própria ideia de "administração de carreira", que compreende o planejamento, organização e direção das aspirações, concepções e atitudes individuais (Santos, 2008), se articula fortemente com a condução dos anos finais da escolarização, quando os jovens já começam a projetar seu futuro profissional. Quando interrogados sobre o que pretendem fazer após a conclusão do Ensino Médio, 40,9\% dos jovens da pesquisa responderam que desejam fazer uma faculdade e trabalhar; $15,5 \%$ indicaram que pretendem fazer um curso técnico profissionalizante e trabalhar e $14,5 \%$ indicaram que passar pelo vestibular e pela prova do ENEM seriam as metas mais imediatas. Diante desse resultado, podemos verificar que $56,4 \%$ dos jovens pensam em continuar os estudos e ao mesmo tempo trabalhar, sendo que prosseguir com os estudos é desejável por 70,9\% dos estudantes. Existe aí uma relação estreita entre estudo e trabalho, em meio ao prolongamento dos estudos para aquisição de competências à

\footnotetext{
14 Segundo os dados da nossa pesquisa, $21,3 \%$ dos estudantes da amostra afirmam que a desmotivação e o desinteresse dos jovens pela escola é o principal problema da escola. Além disso, $79,9 \%$ dos estudantes da pesquisa não permanecem na mesma escola desde o início da formação, chegando a fazer até mais de 5 transferências em sua trajetória escolar.
} 


\section{Trabalhonecessário}

Issn: 1808 - 799X

ano 14, número $24-2016$

empregabilidade e a inserção "melhorada" no mundo do trabalho. Como dizem Rummert, Algebaile e Ventura (2012), a ideia de empregabilidade associada a uma demanda particular de qualificação da força de trabalho encobre as teias da expropriação ${ }^{15}$.

Além disso, de acordo com Gentili (1999), a ideia de empregabilidade, que remonta a teoria do capital humano em uma versão "flexível", traduz uma discurso cínico que enfatiza que a educação e a escola constituem uma esfera de formação para o mundo do trabalho, mas isso passa a depender, agora, do esforço e das competências adquiridas por cada um. Assim, a empregabilidade é um discurso competente que se afasta do direito à educação e tem implicado a "desvalorização do princípio (teoricamente) universal do direito ao trabalho e, de forma associada, uma revalorização da lógica competitiva interindividual na disputa pelo sucesso num mercado estruturalmente excludente" (Gentili, 1999, p.54).

\section{Malabaristas no trabalho e na vida: a promessa do empreendedorismo}

Diante da realidade do desemprego, outra ideia muito difundida como forma dos indivíduos se inserirem no mundo produtivo, é desenvolvendo a capacidade de ser "empreendedor" do próprio trabalho. Então, cabe ao jovem buscar suas próprias opções de trabalho, de maneira autônoma, criativa, driblando as situações adversas, sendo persistente, motivado, controlando seu próprio destino (Coan; Shiroma, 2013). Esse movimento vem crescendo no mundo e especialmente no Brasil. De acordo com relatório da Global Entrepreneurship Monitor (GEM), associada à Fundação Getúlio Vargas (FGV) e

\footnotetext{
15 Fontes (2010) denomina de expropriações secundárias os processos de intensificação da extração de mais-valor, que se manifestam sob formas de exasperação da disponibilidade dos trabalhadores para o mercado.
} 


\section{Trabalhonecessário}

Issn: 1808 - 799X

ano 14 , número $24-2016$

ao Serviço Brasileiro de Apoio às Micro e Pequenas Empresas (SEBRAE), a taxa de empreendedores cresceu de 20,9\% em 2002 para 34,5\% em 2014.

Longe de ser mera coincidência, o slogan do empreendedorismo também vem crescendo entre os projetos profissionais de jovens estudantes de tal modo que, em nossa pesquisa, $17,5 \%$ deles indicaram ter um projeto que lhes permita ser empreendedor ou autônomo. Esse ainda não é o maior percentual, uma vez que $29,9 \%$ deles indicou ter um projeto que o realize profissionalmente. Ocorre que esse desejo de realização profissional, no quadro de desemprego estrutural, é capturado pelo feitiço do empreendedorismo, uma vez que os jovens acreditam encontrar neste caminho a possibilidade de realização de seu projeto profissional. Entre as opções de resposta exclusivas para os estudantes do Ensino Médio, apareceu ainda que $18,2 \%$ deles pretendem realizar concurso público e enquanto que $20,8 \%$ não teriam nenhum projeto profissional no momento.

É salutar o desejo dos jovens de se realizarem profissionalmente, sobretudo em condições de estabilidade econômica, como é o caso daqueles que intencionam fazer concurso público. Porém, diante de incertezas e da necessidade de garantir a subsistência, muitos jovens se veem ainda sem nenhum projeto, resignando-se, muitas vezes, às ofertas que aparecem. $O$ fato de que muitos jovens não tenham ainda nenhum projeto profissional é também expressão de um processo de alongamento dessa fase da vida (15 a 29 anos), para ambas as classes sociais, porém, com consequências mais graves para os jovens trabalhadores. A falta de autonomia financeira e as dificuldades cada vez maiores de obtenção de um emprego estável, frente a ausência de projetos que confrontem, ao menos em parte, a mera submissão do jovem ao que o mercado Ihe oferece, contraditoriamente, concorrem para converter os jovens trabalhadores em exército de reserva, os quais se submetem às opções ainda mais precárias de trabalho.

$\mathrm{Na}$ realidade, tanto os jovens que não possuem quanto os que formulam algum projeto profissional, se chocam com a lógica da "exclusão includente" e 


\section{Trabalhonecessário}

Issn: 1808 - 799X

ano 14, número $24-2016$

também de "inclusão excludente". Conforme Kuenzer (1999), são criadas várias estratégias de exclusão do trabalhador do mercado formal, com vistas a ampliação das margens de lucro do capital, ao mesmo tempo em que são colocadas outras estratégias de inclusão do trabalhador no mercado em condições mais precárias, como é o caso das terceirizações e do estímulo à criação do seu próprio negócio - o empreendedorismo. Por outro lado, estimula-se a inclusão dos indivíduos em diversos níveis e modalidades de educação que, supostamente, preparem "homens e mulheres flexíveis, capazes de resolver problemas novos com rapidez e eficiência, acompanhando as mudanças e educando-se permanentemente" (Kuenzer, 1999, p. 92).

Verifica-se, assim, que a ideia do empreendedorismo encontra eco nos projetos profissionais dos jovens estudantes. Isso porque, entre não ter nenhum projeto profissional e atuar em qualquer atividade que não corresponda aos ideais de realização profissional, ou poder fazer algo que, acredita-se, venha ao encontro de uma atuação profissional mais autônoma e condizente com 0 desejado, a propaganda do empreendedorismo acaba sendo incorporada, ainda que seja uma falácia, posto que tornar-se empreendedor não melhora necessariamente a condição do trabalhador no mercado flexível, pelo contrário, a torna mais instável. ${ }^{16}$

Assim, apesar do empreendedorismo parecer, a princípio, uma alternativa de projeto profissional que liberta o indivíduo da submissão da venda da força de trabalho a outrem, apresentando-se ao jovem como promessa de liberdade para determinar sua própria forma de trabalhar, ao analisar as relações constituídas na compra e venda de mercadorias, a sujeição ao capital ainda se manifesta no tipo de produto que deve ser produzido para ter "aceitação no mercado", nos insumos que devem ser adquiridos para produção, na quantidade necessária a ser

\footnotetext{
${ }^{16}$ Boa parte dos empreendimentos considerados "estabelecidos" tem baixo faturamento (até $\mathrm{R} \$$ $12.000,00$ anual) $(47,8 \%)$, não possuem registro formal (75\%), atuam em segmentos com muitos concorrentes $(69,3 \%)$ e não geram nenhum emprego (79,5\%) (Gem, 2014) e cerca de $27 \%$ das micro e pequenas empresas fecham após dois anos de abertura (Sebrae, 2013).
} 


\section{Trabalhonecessário}

Issn: 1808 - 799X

ano 14 , número $24-2016$

"entregue aos clientes", por exemplo. Ou seja, as atividades empreendedoras permanecem organizadas a partir da lógica do mercado, não criando mais-valia diretamente, mas contribuindo para acumulação do capital.

Dessa forma, ainda que alguns desses jovens tenham projetos profissionais mais concretos e mais determinados que outros, o que se percebe é que muitos ficam apenas no plano do desejo, pois nem sempre são possíveis na realidade, considerando a instabilidade da trajetória escolar, das relações de trabalho e também da vida desses jovens, obrigados a fazer malabarismos para responder por demandas imediatas de sobrevivência. Já aqueles que compram a ideia do empreendedorismo correm o risco de se tornarem coparticipes dos processos de expropriação.

\section{Autorresponsabilização, o esforço pessoal e a competência}

A partir da ótica da individualização, é o próprio sujeito que deve encontrar uma forma criativa de lidar com as adversidades. Vende-se a ideia de que, mesmo enfrentando dificuldades na formação, na família, na vida social ou financeira, é possível superar os obstáculos e vencer a partir de sua "força de vontade" e do "esforço pessoal". Então, surge o discurso de que a ascensão e o sucesso profissional não dependem diretamente do contexto em que se vive, mas sim de características individuais e da competência de cada um. "Nós somos, de agora em diante, intimados a nos tornar os empresários de nossas próprias vidas" (Ehrenberg, 2010, p. 16), ou seja, existe um culto às capacidades do indivíduo, colocadas como determinantes para este ocupar a posição que deseja.

Nesse contexto de hipervalorização das competências individuais descoladas de qualquer influência social, o jovem deve fabricar sua própria trajetória, e seu sucesso ou fracasso são proporcionais aos seus esforços. Dessa forma, legitimam-se as desigualdades a partir do mérito, ou seja, o desempenho é 


\section{Trabalhonecessário}

Issn: 1808 - 799X

ano 14, número $24-2016$

visto como um critério legítimo de ordenação social, considerando o pressuposto de que todos os indivíduos são iguais, autônomos e tem as mesmas oportunidades, diferindo-se apenas por seus recursos pessoais (Barbosa, 1999). Coadunando-se a essa questão, está a ideologia das competências, que ratifica as diferenças de inserção no mercado de trabalho a partir das competências desenvolvidas individualmente. De acordo com Chauí (2014, p. 57), a ideologia das competências

oculta a divisão social das classes, mas o faz com a peculiaridade de afirmar que a divisão social se realiza entre os competentes (os especialistas que possuem conhecimentos científicos e tecnológicos) e os incompetentes (os que executam as tarefas comandadas pelos especialistas). A ideologia das competências realiza a dominação pelo descomunal prestígio e poder do conhecimento científico-tecnológico [...]

Portanto, percebe-se que as competências aparecem como valoresfetiche ${ }^{17}$, conforme indica Alves (2008), que movem as individualidades de classes e ocultam a dimensão histórica das questões. Apesar disso, a ideologia das competências influenciam fortemente a elaboração dos projetos profissionais dos jovens, na medida em que eles assimilam a autorresponsabilização e o esforço pessoal como motores de produção da vida humana. Mas ao realizarmos uma análise de totalidade, histórica e concreta, percebemos que as relações sociais se organizam a partir da forma de produzir a vida humana e não o contrário. De acordo com Marx (2008, p.47),

na produção social da sua vida, os homens entram em determinadas relações, necessárias, independentes da sua vontade, relações de produção que correspondem a uma determinada etapa de desenvolvimento das suas forças produtivas materiais. O conjunto dessas relações de produção forma a estrutura econômica da sociedade, a base real

\footnotetext{
17 O termo valor-fetiche foi apresentado por Alves (2008, p. 35) para designar "nexos ideológicos do novo produtivismo que se disseminam pela sociedade burguesa". Segundo o autor, esses valores-fetiche são inovações sócio-metabólicas que compõem o processo de reestruturação.
} 


\section{Trabalhonecessário}

Issn: 1808 - 799X

ano 14 , número $24-2016$

sobre a qual se levanta a superestrutura jurídica e política e à qual correspondem determinadas formas de consciência social. [...] condiciona o processo da vida social, política e espiritual em geral.

Nesse sentido, cabe analisar os elementos da base material que determinam as condições para a elaboração dos projetos profissionais que legitimam a reprodução de tais ideologias. É que no atual estágio de desenvolvimento das forças produtivas materiais o trabalho não é mais vivido como elemento de mediação de primeira ordem ${ }^{18}$, subordinado ao planejamento e à vontade de quem o produziu (Marx, 1996); está subordinado ao acúmulo de capital e não ao atendimento das necessidades humanas. Nesse tipo de mediação de segunda ordem ${ }^{19}$, os elementos que compõem 0 trabalho se reorganizam, pois, os instrumentos e objetos de trabalho estão sob o domínio privado e o fim último do trabalho não é apenas produzir seu valor-de-uso e sim, criar valor-de-troca. Como disse Marx (1996, p. 320), "o processo de trabalho é um processo que ocorre entre coisas que o capitalista comprou, entre coisas que Ihe pertencem".

Dessa maneira, o que importa não é a perspectiva qualitativa do processo de trabalho segundo seu objetivo e conteúdo, mas sim sua dimensão quantitativa, na relação entre quantidade de tempo trabalhado, de insumos utilizados e de produtos produzidos, ou seja, o trabalho reduz-se a dimensão instrumental, alienando-se do seu valor-de-uso. A partir do momento que a atividade do próprio trabalho pertence a outro, ele não é mais visto como atividade vital, em seu potencial criador, transformador, mas apenas um meio para manutenção da sua existência. Nesse sentido, o indivíduo passa a "existir primeiro como trabalhador e, segundo, como sujeito físico" (Marx, 1989, p.152).

\footnotetext{
${ }^{18} \mathrm{O}$ trabalho é a mediação fundamental entre homem e natureza (Meszáros, 2006).

${ }^{19}$ Meszáros (2006, p. 78 grifo do autor) esclarece que a instituição da propriedade privada, a divisão social do trabalho e o intercâmbio das mercadorias se instituem as mediações de segunda ordem que são "historicamente específicas da automediação ontologicamente necessária [...] como forma específica, alienada".
}

TrabalhoNecessário - www.uff.br/trabalhonecessario; Ano 14, № 24/2016. 


\section{Trabalhonecessário}

Issn: 1808 - 799X

ano 14, número $24-2016$

Por isso, o homem não se vê mais parte da natureza, mas se percebe individualmente, de modo parcelar, e essa visão fracionada e individualizante produzida pela alienação influencia diretamente na relação com os outros homens, pois "o que vale para a relação do homem com seu trabalho, com o produto do seu trabalho e consigo mesmo, isto vale para a relação do homem com o outro homem, bem como com o trabalho e o objeto de trabalho do outro homem" (Marx, 1989, p. 158). Ou seja, a alienação objetifica, inclusive, a relação entre os homens, com seu próprio gênero humano.

A partir do estabelecimento da alienação do trabalho, as relações entre os homens também se tornaram reificadas, coisificadas, fetichizadas. Esse processo se traduz, por exemplo, no amplamente difundido discurso da necessidade de adaptação do perfil profissional do individuo às exigências do mercado de trabalho. Nesse sentido, o termo "mercado de trabalho" também se torna um fetiche, como se fosse uma entidade autônoma que comanda os critérios de classificação dos postos de trabalho e os requisitos que devem ser preenchidos para ocupá-los. Entretanto, essa visão fetichizada omite as reais relações entre homens concretos que, de um lado, oferecem força de trabalho e, de outro, a procuram. Dessa forma, as "exigências do mercado de trabalho" são estabelecidas pelo conjunto dos compradores de força de trabalho que, de acordo com a relação oferta e demanda e a complexidade das tarefas a serem realizadas, podem aumentar ou diminuir o nível dos requisitos. Esse processo de reificação suplanta inclusive a dimensão histórica das relações sociais e por consequência, produz a naturalização dessas relações tais como se configuram, sem questionamentos. Nas palavras de Meszáros (2006, p. 79) "a mediação de segunda ordem aparece como mediação de primeira ordem, isto é, como fator ontológico absoluto", ou seja, incontestável e sem alternativas de transformação. Isto posto, o indivíduo é visto como desligado de laços naturais e históricos (Marx, 2008). 


\section{Trabalhonecessário}

Issn: 1808 - 799X

ano 14, número $24-2016$

Nesse contexto, ao passo que os projetos profissionais são elaborados a partir de um ponto de vista unicamente individual, desconsiderando o conjunto das relações de produção da vida material, também é possível dizer que estes se constituem de forma alienada. Isso por que, a partir do momento que os jovens passam a orientar seus projetos profissionais segundo as exigências do mercado de trabalho, reproduzindo os princípios da competitividade, meritocracia, produtividade e eficiência, também subordinam sua vontade à uma dimensão instrumental. Nesse sentido, o que importa é a autorresponsabilização do indivíduo em acumular certificações e qualificações que "agreguem valor" ao seu currículo, tornando-o mais produtivo e polivalente, uma mercadoria mais interessante. Sendo assim, a quantidade de competências desenvolvidas é atribuída ao esforço pessoal e não ao contexto real em que se vive.

\section{Passaporte para o futuro profissional: concorrência e certificação}

No processo de expansão capitalista, as formas de exploração do trabalho humano vão mudando em sua aparência, mas continuam produzindo mais-valia em sua essência. O processo de desenvolvimento das forças produtivas complexifica as relações de trabalho e exige, por sua vez, o amoldamento subjetivo dos trabalhadores. Para dar conta disso, a escola é requerida a assumir o papel de formar a força de trabalho adequada às diferentes conformações da atividade produtiva, correspondentes aos diversos graus da divisão social e técnica do trabalho.

A partir das relações de produção no contexto do capital-imperialismo, e da forma atual de organização do trabalho, são concebidos e veiculados novos modos de vida, comportamentos e atitudes. Nesse sentido, se o fundamento do trabalho é a fragmentação, então, tanto as relações sociais e produtivas, como a escola educam o trabalhador para essa divisão. $E$ se a flexibilização, a 


\section{Trabalhonecessário}

Issn: 1808 - 799X

ano 14, número $24-2016$

empregabilidade, a responsabilidade individual, a concorrência e o empreendedorismo imprimem ideias e valores na atual configuração do trabalho, então, as relações sociais e a escola conjugam esforços para educar nesta direção (Kuenzer,1999).

Em nossa pesquisa, identificamos que $29,2 \%$ dos jovens confirmam que 0 esforço pessoal é elemento fundamental para um bom desempenho na escola. Isso significa que a "força de vontade", a "autorresponsabilização" e o "esforço pessoal" são vistos como valores condutores das atitudes e comportamentos, não só frente aos estudos, mas diante da vida. Dessa forma, para vencer a concorrência no mundo do trabalho, os jovens se veem obrigados a se qualificar constantemente e, nesse sentido, a escola é quem fornece as credenciais básicas para isso.

Entre os estudante do Ensino Médio, 49,6\% deles dizem que vão à escola para adquirir conhecimento e 31,9\% porque desejam melhorar o seu futuro e de sua família. Isto revela uma crença na escola e em sua função qualificadora e certificadora, uma vez que a escola deve conferir as competências mínimas para que os jovens se tornem empregáveis. Assim, tornar-se empregável configura-se como um discurso competente que penetra os projetos profissionais dos jovens, ainda que a propalada "educação para a empregabilidade" seja uma formação educação para o desemprego (Gentili, 1999, p. 78). Em outros termos, como dissemos antes, a ideia de empregabilidade associada à exigência de formação ou mesmo de escolarização, esconde a desintegração do direito à educação, ao mesmo tempo que reforça a lógica da concorrência e da competição individual na disputa pelo sucesso profissional, frente a um mercado de trabalho dominado pelos interesses da acumulação privada.

Colada a essa ideia da formação para o desemprego, o empreendedorismo aparece como "tábua de salvação". Enquanto cria a ilusão da autonomia, da liberdade, da ampliação do tempo livre para si, do sucesso e da realização profissional, joga os trabalhadores "aos leões", uma vez que, enquanto "pessoa 


\section{Trabalhonecessário}

Issn: 1808 - 799X

ano 14 , número $24-2016$

jurídica" esses jovens empreendedores são submetidos às mesmas regras de concorrência inter-capitalista que praticam as grandes empresas e, nestas circunstâncias, como a tendência do capital é produzir monopólios, os pequenos negócios são abatidos ou simplesmente derrotados pelos grandes conglomerados.

Além disso, como as relações de produção são cada vez mais desumanizantes e alienadoras, a subjetividade humana tende a ser também cada vez mais alienada, domesticada e ajustada às determinações das condições objetivas. Considerando que a consciência é expressão da forma como cada indivíduo se apropria do conjunto de relações sociais nas quais está inserido, a ofensiva do capital não se restringe apenas ao trabalho e à produção propriamente dita, mas à formação das consciências individuais. Nesse sentido, por mais que a elaboração dos projetos profissionais sejam processos individuais, que comportam desejos e interesses pessoais, eles não estão apartados do contexto de relações sociais de produção da vida (até por que os próprios desejos e interesses se constituem nas relações sociais entre os homens), ainda que muitos jovens não percebam isso.

É certo que os jovens estudantes da nossa pesquisa, se não possuem um projeto profissional claro e determinado por outros princípios que se confrontem as ideias e valores da concorrência capitalista, do mérito, do individualismo competitivo, enfim do ajustamento às atuais relações de produção, ao menos eles possuem expectativas. Todavia, enquanto os projetos profissionais dos jovens da classe trabalhadora tendem a ficar muito mais no plano do desejo, ou seja, são muito mais imaginários que reais, tal como atestam os estudos de Silva (2015), as expectativas, que são mais imediatas, pontuais e de curto prazo, acabam por responder às demandas do mercado e das relações de trabalho no atual contexto da flexibilização, o que implica maior instabilidade, precariedade, expropriação e desumanização do trabalhador. 


\section{Trabalhonecessário}

Issn: 1808 - 799X

ano 14, número $24-2016$

Finalmente, cabe mencionar que a escola, como mediadora fundamental da elaboração dos projetos profissionais dos jovens, se pouco ou nada tem contribuído para a apropriação de conhecimentos que permitam a compreensão crítica da realidade em que vivem e sua transformação em ação, em organização da classe trabalhadora e em movimento de ruptura com a lógica e as condições objetivas reinantes, acaba por cumprir um papel funcional ao capital, produzindo justamente aquilo que o mercado requer de um tipo de formação para o trabalho simples, isto é, nos termos de Kuenzer (1999, p. 93), uma "certificação vazia", que significa um conjunto de estratégias que visam a substituir a educação básica como direito à formação integral (omnilateral) por "modalidades aparentes de inclusão que fornecerão a justificativa, pela incompetência, para a exclusão do mundo do trabalho, dos direitos e das formas dignas de existência".

Voltando a Marx (1989), enquanto a atividade vital do homem - que é o trabalho - for apropriada por outro homem, ela deixa de ser uma atividade criativa, potencializadora das capacidades humanas, portanto, transformadora. Como tal, o trabalho se reduz à condição de subsistência e nesse sentido os jovens são limitados em sua capacidade de projetar seu futuro e de seu desenvolvimento pessoal e profissional, na medida em que se veem obrigados a produzir sua imediata existência. Assim, são poucos os jovens que conseguem resistir e recusar as ideias e valores hegemônicos a ponto de realizar seu projeto profissional na direção de outro projeto que implique em conquistas ao processo de emancipação humana.

\section{REFERÊNCIAS}

ALVES, G. A. P. Trabalho e Subjetividade: metabolismo social da reestruturação produtiva do capital (2008) 190f. Tese (Doutorado) UNESP - Marília, 2008. Disponível em: $<$ https://incubadorasocialpucrs.files.wordpress.com/2013/12/trabalho-esubjetividade.pdf>. Acesso em 24 abr. 2016. 


\section{Trabalhonecessário}

Issn: 1808 - 799X

ano 14 , número $24-2016$

ANTUNES, R. L. C. Adeus ao trabalho? Ensaio sobre as metamorfoses e a centralidade do mundo do trabalho. 8. ed. São Paulo: Cortez: Ed. Unicamp, 2002.

BARBOSA, L. Igualdade e meritocracia: a ética do desempenho nas sociedades modernas. 2ª ed. São Paulo: FGV, 1999.

BRASIL. Portal do Microempreendedor - MEI. Acesso à informação: Governo Federal. 2016. Disponível em: <http://www.portaldoempreendedor.gov.br/meimicroempreendedor-individual>. Acesso em: 24 abr. 2016.

CASTRO, R. P. Escola e mercado: escola face à institucionalização do desemprego e da precariedade na sociedade colocada ao serviço da economia. Revista Perspectiva. v. 22, n.1. 2004.

CHAUÍ, M. A ideologia da competência. v. 3. São Paulo: Editora Perseu Abramo, 2014.

COAN, M; SHIROMA, E. O. Educação para o empreendedorismo: forjando um jovem de novo tipo? In: SILVA, M. M; QUITEIRO, E. M.; EVANGELISTA, O. (org.) Jovens, Trabalho e Educação: a conexão subalterna de formação para o capital. Campinas: Mercado das Letras, 2013.

EHRENBERG, A. O Culto da Performance: Da Aventura Empreendedora à Depressão Nervosa. Tradução: Pedro Fernando Bendassolli. São Paulo: Ideias \& Letras, 2010.

FONTES, V. O Brasil e o Capital-imperialismo: teoria e história. $2^{\underline{a}}$ ed. EPSJV/Editora UFRJ: Rio de Janeiro, 2010.

GENTILLI, P. Educar para o desemprego: a desintegração da promessa integradora. In: FRIGOTTO, G. Educação e crise do trabalho: Perspectivas de

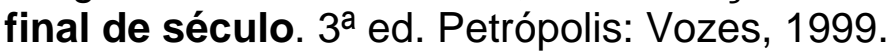

GENTILI, P. Trabalho e Educação em tempos neoliberais. In: LOMBARDI, J. C. et. al. Capitalismo, Trabalho e Educação. São Paulo: Editores Associados, 2002.

GEM. Global Entrepreneurship Monitor. Empreendedorismo no Brasil Relatório Executivo. 2014. Disponível em: http://www.sebrae.com.br/Sebrae/Portal\%20Sebrae/Estudos\%20e\%20Pesquisas/ gem\%202014_relat\%C3\%B3rio\%20executivo.pdf. Acesso em: 26 abr. 2016.

GHINATO, P. Elementos Fundamentais do Sistema Toyota de Produção. In: ALMEIDA, A. T. de; SOUZA, F. M. C. Produção e Competitividade: Aplicações e Inovações. Recife: Editora UFPE, 2000. 
Issn: 1808 - 799X

ano 14, número $24-2016$

HARVEY, D. Condição pós moderna. 2ª ed. São Paulo: Loyola, 2002.

KUENZER, A. Z. Exclusão includente e inclusão excludente: a nova forma de dualidade estrutural que objetiva as novas relações entre trabalho e educação. In: LOMBARDI, J. C. et. al. Capitalismo, Trabalho e Educação. São Paulo: Editores Associados, 1999.

MARX, K. Contribuição a crítica da economia política. $2^{\underline{a}}$ ed. São Paulo: Expressão Popular, 2008.

MARX, K. O capital: crítica da economia política. Livro I, v. 1.13 ed. Rio de Janeiro: Nova Cultura, 1996.

MARX, K. Trabalho e superação positiva da auto-alienação humana. In: FERNANDES, F. (ORG.) K. Marx F. Engles: História. 3 ed. São Paulo: Ática, 1989.

MESZÁROS, I. A educação para além do capital. In: . O desafio e o fardo do tempo histórico. São Paulo: Boitempo, 2007.

MESZÁROS, I. A teoria da alienação em Marx. São Paulo: Boitempo, 2006.

MONTAÑO, C.; DURIGUETTO, M. L. Estado Classe e Movimento Social. $3^{a}$ ed. Cortez: São Paulo, 2002.

OLIVEIRA, F. A crítica a razão dualista: o ornitorrinco. São Paulo: Boitempo, 2003.

RUMMERT, S. M.; ALGEBAILE, E.; VENTURA, J. Educação e Formação Humana no cenário da integração subalterna no capital imperialismo. IN: SILVA, M. M; QUITEIRO, E. M.; EVANGELISTA, O. (org.) Jovens, Trabalho e Educação: a conexão subalterna de formação para o capital. Campinas: Mercado das Letras, 2013. p.15-70.

SANTOS, R. M. N. G. S. O papel dos indivíduos e das organizações na gestão e desenvolvimento da carreira: Um estudo de caso. Dissertação (Mestrado Integrado em Psicologia) - Universidade de Lisboa, Lisboa, 2008. Disponível em: <http://repositorio.ul.pt/handle/10451/696>. Acessado em: 10 abr. 2016.

SEBRAE. Sobrevivência das empresas no Brasil. Coleção estudos e pesquisas. Brasília, 2013. Disponível em: <http://www.sebrae.com.br/Sebrae/Portal\%20Sebrae/Anexos/Sobrevivencia_das_ empresas_no_Brasil=2013.pdf>. Acesso em: 24 abr. 2016. 
Issn: 1808 - 799X

ano 14 , número $24-2016$

SENNETT, R. A corrosão do caráter: consequências pessoais do trabalho no novo capitalismo. Rio de Janeiro: Record, 2002.

SILVA, Mariléia Maria da. Entre "plano b" e "saídas de emergência": percursos e expectativas profissionais de jovens trabalhadores/as. In: Revista Trabalho Necessário, v. 13, n. 21. Rio de Janeiro: UFF, maio/ago. 2015. Disponível em: $<$ http://www.uff.br/trabalhonecessario/images/TN_21/6_Artigo.pdf >. Acesso em: 29 maio 2016

TRADING Economics. Taxa de desemprego: lista de países. 2016. Disponível em: <http://pt.tradingeconomics.com/country-list/unemployment-rate>. Acesso em 24 abr. 2016.

Recebido: 27 de junho de 2016

Aprovado: 04 de agosto de 2016 